THE UNIFORM SUCCESS OF SEGREGATION MIEASURES IN ERADICATING KALA-AZAR FROM ASSAM TEA GARDENS:

ITS BEARING ON THE PROBABLE MODE OF INFECTION. BY

J. DODDS PRICE, M.R.C.S., L.R.C.P., AND

LEONARD ROGERS, M.D., I.M.S.

Is 1906-7 we investigated together the problem of the epidemiology of kala-azar on tea gardens in the Nowgong district of Assam under very favourable conditions for obtaining accurate data. Previous to that time Dodds Price had for several years watched the insidious invasion of the coolie lines of the tea estates from the neighbouring villages by the terrible epidemic of liala-azar which was then sweeping through the Nowgong district in a wave of such relentless severity that it caused an actual decrease of no less than $31.5 \mathrm{per}$ cent. in the population during the decade 1891-1901, against an increase of $16.3 \mathrm{per}$ cent. in the unaffected Lakhimpur district. As a result of a sad experience he had come to the conclusion that the disease was certainly communicable, and had consequęntly arranged early in 1895 for new lines to be built for a number of freshly imported coolies arriving on the Rangamati tea estate. Rogers commenced his investigations in the Nowgong district in $\Lambda$ pril, 1896, and as the result of detailed inquiries he independently arrived at the conclusion that the infection was a house one, as fully recorded in his original report of 1897 and in Fcvers in the Tropics.

On investigating together, in 1897, the effects of bringing into use the new lines at Rangamati, we found that no case of kala-azar had occurred among 150 coolies who had then resided there for-two years. Yet out of 50 coolies of the same batch who had been living in the old infected lines, for want of room in the new ones, no fewer than 16 per cent. were already dead of kala-azar, while others wore suffering from the disease, and that in spite of the fact that the new lines were situated only 300 yards from the old ones.

It was therefore decided to carry ont a further experiment, suggested by Rogers, to ascertain if the disease could be stamped out of already infected coolie lines by moring out all the healthy persons into newly built lines, and segregating the remaining infected families. As it was then impossible to diagnose the disease in its early stages from ordinary malarial fever (kala-azar being at that time regarded by us as a peculiar severe cpidemic form of malaria), it was decided to move into the new lines no person in whose household any cases of kala-azar had occurred, iest some of them might already be suffering from an early stage of the disease, and thus carry the infection with them. 'This experiment was carried out at the Old Solona out-garden lines of the Rangamati estate. The infection was so serere in this community that no fewer than 144 out of 240 souls had cases of the disease in their households, so that only the remaining 96 people could be moved, while 5 of these had to be sent back very soon after on account of developing fever. The new line was filled up with freshly imported coolies, who now number 800 workers, and to this day - that is, for sixteen year's-they have remained absolutely free from kala-azar. Of the 96 people who had to be left in the old infected lines nearly all contracted the disease and died of it during the next few ycars. Moreover the kala-azar spread to a contiguous line with 60 healthy coolies, who had worked for years on the estate, and who rofused to move into new lines. One-third of them died of the disease within the next fiftcen months, and the rest ncarly all succumbed or left the cstate during the few succeeciing years. Their luts have now ceased to exist. and with them the dread disease has disappeared from that neighbourhood. Nevertheless, the new lines--which have now remained free from kala-azar for sixteen years - are only 400 yards from the old ones, which continued to suffer so severely for several years after the new lines were inhabited.
The remarkably successful result obtained in this first experiment, the earlier phases of which have already been recorded by Rogers, has encouraged other tea-garden managers and directors to allow Dodds Price to repeat the procedure in connexion with coolie lines infected by kalaaz̃ar. We have recently studied the results obtained during the last sixteen years, and think they are worthy of record, as they have been uniformly suecessful, and absolutely prove the soundness of the measure based on our epidemiological studies of kala-azar, thus rendering this measure one of the first importance in dealing with the most terrible disease of India, and also throwing considerable light on the probable mode of infection.

In order to bring out the facts in as condensed and con. venient a form as possible, the most essential data, as far as they are available, regarding the infected Nowgong tea gardens are shown in Table I. Column 1 shows the working population of each line at the present time, to which must be added from 20 to 25 per cent. to allow for young children. Then follow the dates on which the lines became infected with kala-azar; the approximate number of deaths before the lines were moved, the figures being on the conservative side, and to some extent inderestimating the real loss; succeeding columns give the years in which the new lines were built, which was almost always in the non-manufacturing cold season; the approximate number of persons with infection in their households, who were left on the old site or in a segregation camp, and the number of deaths from kala. azar which subsequently occurred among them. The dis. tance of the new lines from the old infected ones and the number of years which the new lines have now remained free from the disease complete the table. As there have been no matcrial extensions of the area under tea in tho

TABLE I.

\begin{tabular}{|c|c|c|c|c|c|c|c|c|}
\hline Tea Estate. & 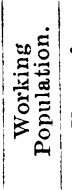 & 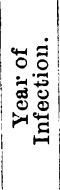 & 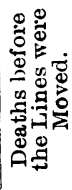 & 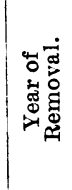 & 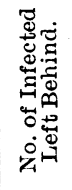 & 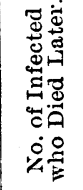 & 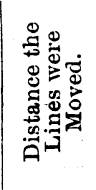 & 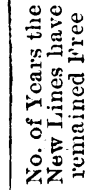 \\
\hline New Rangamati & 622 & - & - & 1895 & 一 & - & $300 \mathrm{yds}$. & \\
\hline a(Ran- & 800 & 1893 & $\begin{array}{l}\text { over } \\
200\end{array}$ & $1897-8$ & 140 & $\begin{array}{l}\text { fully } \\
112\end{array}$ & 400 yds. & s. \\
\hline Haspani & 625 & 1897 & about & 1899 & over & at least & $800 \mathrm{yds}$. & srs. \\
\hline Kondoli & 600 & 1892 & over & 1901 & $?$ & a few & - & $12 \mathrm{srs}$. \\
\hline Kellydene & 900 & 1895 & 320 & $1902-3$ & about & about & 750 yds. & siss. \\
\hline Amlucki & 1,800 & 1896 & 350 & $1900-1$ & about & 47 & $\frac{1}{2}$ mile & 13 srs. \\
\hline Lung Soong ... & 540 & 1902 & about & $1904-5$ & sbout & 15 & $800 \mathrm{yds}$. & 8 srs. \\
\hline Nonoi $\ldots$ & 312 & 1893 & about & $1905-6$ & $\begin{array}{l}\text { about } \\
40\end{array}$ & about & ${ }_{4}^{3}$ mile & yrs. \\
\hline Meesa ... & 550 & 1896 & over & $1905-6$ & 25 & 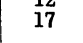 & $603 \mathrm{yds}$. & $8 \mathrm{yrss}$ \\
\hline Seconee... & 678 & 1908 & 128 & 1911 & 98 & 23 & 600 yds. & $\cdot 2 !$ \\
\hline Totals & 6,727 & $\div$ & 1,393 & - & 698 & 361 & & \\
\hline $\begin{array}{l}\text { Deaths per } \\
\text { mille }\end{array}$ & - & - & 207 & - & - & 517 & & \\
\hline
\end{tabular}

Nowgong district during the period of time dealt with, owing to the difficulty in increasing the labour force, the present working population of the coolie lines is much the same as formerly. It thus appears that in the ten lines shown in Table I kala-azar lias been stamped ont of a labour force of nearly 7,000 workers, after it had caused $a$ mortality within a few year's of 207 per mille, and although, subsequently to moving the coolie lines, over lialt of the infected households which had to be left behind on the infected sites died of the disease. As it costs from $£ 7$ to $£ 14$ to recruit a coolie, and the average duration of the illness is at least seven months, during which food and treatment costs $£ 4$, it is clear that, in addition to the great saving of life and suffering, the financial aspect of the case to the tea industry is of great importance.

In order to make matters quite clear, it will be well to give further details regarding certain of the instances recorded in Table I. For this purpose one that happened a number of years ago and one of quite recent date haro been selected, solely because more detailed records are [277.1] 
available concerning them, while each contained but a single coolie line, which simplifies the descriptions.

The Amlickie Tea Garden Outbrcali of 1896-1901.

Kala-azar commenced on this garden in 1896 and got a strong footing in the following year. It raged during 1898 to 1900, when strong action was taken, the immediately beneficial results of which will be evident from the figures given in Table II.

TABLE II.-Yearly Total Deathis and Deaths from Kala-azar ät Amllickicie.

\begin{tabular}{c|c|c|c|c}
\hline Year. & $\begin{array}{c}\text { Working } \\
\text { Population. }\end{array}$ & $\begin{array}{c}\text { Total } \\
\text { Deaths. }\end{array}$ & $\begin{array}{c}\text { Kala-azar } \\
\text { Deaths. }\end{array}$ & Remarks. \\
\hline 1899 & 1,074 & 167 & 138 & $\begin{array}{l}\text { Years preceding change } \\
\text { of lines. }\end{array}$
\end{tabular}

\begin{tabular}{l|r|r|r|l}
\multicolumn{5}{|c|}{ New Lines Commenced and Kala-azar Camp Opened. } \\
1901 & 1,026 & 32 & 9 \\
.1902 & 975 & 35 & 10 \\
1903 & 918 & 33 & 15 \\
1904 & 896 & 28 & 13 \\
1905 & 886 & 12 & 0 & \\
1906 & 812 & 25 & 0 & \\
1907 & 809 & 9 & 0 & All in kala-azar camp; \\
$19: 8$ & 985 & 29 & 0 & 212 new coolies imported \\
1909 & 1,006 & 22 & 0 & \\
1910 & 1,001 & 16 & 0 & \\
1911 & 961 & 19 & 0 & \\
1912 & 1,008 & 21 & 0 & \\
\hline Total famine districts. & & & 297 &
\end{tabular}

In the cold weather of $1899-1900$ a site was chosen and new lines commenced, and 347 healthy coolies, with no kala-azar cases in their households, were carefully selected and drafted into the new lines in April, 1900. In the following cold season of 1900-1 fresh houses were added, aud 150 more coolies drafted in, and the lines were inally finished in the winter of 1902-3, when the remaining old healthy coolies, together with freshly recruited ones, were allowed into the new lines. All this time the contacts and kala-azar cases remained in the old lines, and continued to do so until the epidemic ceased simply by killing off the majority of the coolies left on the infected site. It is estimated that about 30 recovered during the peyiod from 1899 to 1905 , or 10 per cent.

It will be seen from the figures in Table II that the mortality from kala-azar in 1899 and 1900 amounted to no less than 128 and 106 per mille, while in the previous two ycar's it had also been very high, although unfortunately the exact figures are not now available. The sudden drop in 1901, after the new. lines had been occunied, to under 9 per mille deathis from liala-azar, and the complete and lasting eradication of the disease within a year after the completion of the new lines, are conclusive in regard to the effertiveness of the measure. It is not too much to say that this fine estate was saved from very great loss, if not ruin, by the measure under consideration. The high case-mortality of about 90 per cent. shows the virulence of the outbreak.

The Seconzec Tea Garden Outbreak of 1908-13.

This garden is situated off the routes of district traffic, and completely escaped infection by kala-azar until some years after the epidemic had died down to a great extent in the Nowgong district, leaving sporadic cases and limited centres of infection. Nevertheless, when the disease did break out on the Seconee estate, it ran an acute epidemic course with a high death-rate, thus showing that tea-garden coolies, who are mainly recruited fróm pàrts of India where kala-azar is comparatively rare or totally unknown, are liable to severe outbrealis of the diserse, should the infection once gain a footing among them. The number of deaths to October 1913 , has been 151 , the complete recoveries amount to 21 , while two cases are still under treatment. Omitting the last two, whose condition is 'still doubtful, the casemortality has been " 87.8 and the recovery-rate 12.2 per cent., or a little over that of the Amluckie outbreak of ten years earlier, thus showing no appreciable diminution in the virulence of the disease.

In May, 1911, the directors gave Dodds Priee a free hand in dealing with the serious situation, and new lines were at once constructed, into which 300 health people were moverl, leaving belrind in the old lines 98 persons with the infection in their houscholds; all the uninhabiteil huts in the old lines were destroyed. Of the 98 people left in the infected lines 23 have died within the ensuing two and a loalf years up to date of writing. These deaths are included in the total loss of 151 persons, being nearly one-fourth of the whole labour force of the estate. Thio new lines are situated some 600 yards from the o!d site, but on higher ground. It is also worthy of noto that, owing to no water being obtainable in the new lines except by digging a deep well, the old well was exclusively used during the first year after the new lines were opened, and it is still used during the dry cold and carly hot weather months, when the supply in the new well runs short. Nevertheless the kala-azar rapidly died out after the lines were moved, only two cases now remaining. Only one of these had lived in the new lines, and he was a bungalow servant, who used also to visit the neighbouring villages and markets. At Seconee, then, there was no change in the drinking water, which can therefore be excluded as being in any way associated with the incidence of the disease. Segregation was adopted here earlier than in the former cases, although not until very serious loss of life had occurred from kala-azar. It was very noticeable at Seconee, as has been the experience of Dodds Price in all former ontbreaks on tea gardens, that it was the acclimatized coolies, who had worked for year's on the estate, who succumbed to kala-azar. Their loss is par. ticularly serious from the labour point of view, as it is now impossible to replace them by an equally good class of workers, and as they are very rarely sick they form the backbone of the labour force.

The rapid success of the measures adopted to separate the healthy from infected families was most gratifying in this instance from the sanitary point of view as well as from the financial standpoint.

\section{The Results of Removal.}

The above two detailed examples, together with the eight other instances summarized in Table I, will suffice to demonstrate how simply and ccrtainly a serious outbreak of kala-azar can be controlled and, within a comparatively short time, completely eradicated from very badly infected coolie lines of tea estates by the measures advocated. In fact, it would be difficult to find a moro successful method of dealing with such a deadly and ruinous human disease in the whole range of preventive medicine. It is particularly worthy of note that this efficacious measure was worked out as a result of epidemio. logical studies, at a time (1896-7) when we were ignorant of the true nature of kala-azar and its mode of infection; while it was not then even known how the infection of malaria itself was conveyed from one person to another. The facts collected having established that the infection clung to the houses or their sites, this sufficed to enable us to evolve a simple plan of dealing effectually with the epidemic which was ravaging the Nowgong district and ruining its chief industry.

\section{The Indefinite Occurrence of Kala-asar in Coolie Lines Once Infected if Segregation Measures are not Carried Out.}

It will be seen from a study of Table $I$ that the segvegation measures were invariably successful at whatever period they were carried out-namely, from 1895 up to 1908. The résults obtained cannot, therefore, be due to the decline of the epidemic in the Nowgong district during the first decade of the present century. Further and absoIntely conclusive evidence to the same effect is furnished by the two control coolie lines, which have not been moved, and which still suffer from the disease to the present moment. The following is a brief account of the course of the disease in these control lines. 
Kata-azar at Solona.

On this estate (which is quite distinct from the old Solona lines of the Rangamati garden) two large coolie lines, called Solone aud Borghot respectively, became infected witli kala-azar as early as 1896. Late in the following year this estate came under the medical care of Dodds Price, when the disense was causing considerable lass of life. Table III shows the number of deaths year by year in each line, and also the mortality during the four years 1897-1900 in the segregation camp, to which all cases of the disease and suspeets were for a time removed.

TABLE III.-Kala-azar Deaths on the Solona Estate from 1897 to 1913 .

\begin{tabular}{|c|c|c|c|c|c|}
\hline Year. & $\begin{array}{l}\text { Solona } \\
\text { Lines. }\end{array}$ & $\begin{array}{c}\text { Borghot } \\
\text { Lines. }\end{array}$ & Total. & $\begin{array}{c}\text { Kala-azar } \\
\text { Cawp. }\end{array}$ & Remarks. \\
\hline 1897 & 45 & 29 & 74 & 80 & \multirow{8}{*}{$\begin{array}{l}\text { Also } 80 \text { deaths be- } \\
\text { fore } 1897 \text {. } \\
\text { Reduction due to } \\
\text { segregation of } \\
\text { cases in kala-azar } \\
\text { camp. }\end{array}$} \\
\hline 1898 & 38 & 37 & $75)$ & & \\
\hline 1899 & 7 & 5 & 12 & 150 & \\
\hline 1900 & 1 & 1 & 2) & & \\
\hline 1901 & 3 & 2 & 5 & - & \\
\hline 1902 & 10 & 4 & 14 & - & \\
\hline 1903 & 15 & 3 & 18 & - & \\
\hline 1904 & 14 & 10 & 24 & - & \\
\hline 1905 & $5)$ & 1) & 6 & - & \multirow{6}{*}{$\begin{array}{l}\text { New lines built at } \\
\text { Amguri for newly } \\
\text { importe } 1 \text { coolies. }\end{array}$} \\
\hline 1906 & 3 & 3 & 6 & - & \\
\hline 1907 & $3 \zeta_{17}$ & 2 & 5 & - & \\
\hline 1928 & $13^{17}$ & 1 & 2 & - & \\
\hline 1909 & 2 & 1 & 3 & - & \\
\hline 1910 & 3) & $1)$ & 4 & - & \\
\hline 1911 & 6 & 7 & 13 & - & \multirow{3}{*}{$\begin{array}{l}\text { Recrudesencedu to } \\
\text { newly impos. } \\
\text { coolies being } \\
\text { again placed in } \\
\text { the old lines. }\end{array}$} \\
\hline 1912 & 8 & 7 & 15 & - & \\
\hline $\begin{array}{c}1913 \\
\text { (Dec. 12) } \\
\end{array}$ & 10 & 14 & 27 & - & \\
\hline Total & 174 & 128 & 302 & 230 & \\
\hline $\begin{array}{l}\text { Popula- } \\
\text { tion }\end{array}$ & 650 & 850 & 1,500 & & \\
\hline
\end{tabular}

It appears from the data given in Table III that the partial measure of removing the evident and suspected cases of kala-azar from the infected lines to a segregation camp during the four years from late in 1897 to 1900 had a very beneficial effect in greatly reducing the number of deaths from the disease subsequently. The kala-azar camp was brolien up at the end of 1900, and two years later the deaths in the old infected lines began to mount once more from 5 in 1901 to 14 in 1902, while the figure reached 24 in 1904. In 1905 a marked decrease again occurred, which lasted for six years. This decline in the disease coincided with the carrying out of the following measures. Disinfection directed towards the clestruction of bed-bugs was carriod out in all the infected houses in the Borghot lines in the hot se tson of 1905, and it is worthy of note in this connexion that the Borghot lines had only about half the number of deaths that occurred in the Solona lines during the following six years, although the population of the former (850) is considerably greater than that of the latter (650). An even more important factor was doubtless the construction of new lines at Amguri, only a few hundred yerds from the old Borghot lines, in the cold season of 1905-6, into which all the newly imported coolies were placed. This new line has remained almost entirely free from kala azar during the last eight years, the few cases which did occur being due to carelessness on the part of the manager in allowing admissions of coolies from the infected lines. In 1901 a distinct recrudescence of the disease took place in the two old infected lines, 52 deaths having occurred within just under three years, undoubtedly due to newly imported coolies being again placed in the old lines, owing to the new ones having become filled up. It is thus abundantly clear that the paitial measures adopted in the case of this estate have failed to eradicate the disease, which has caused more deaths during the first eleren months of 1913 than in any year since 1899, when the kala-azar camp was in full use.

We have here the clearest evidence that as long as fresh material, in the form of newly imported coolies, is introdaced into infected lines, so long will the disease continuo to exact a heary toll in lives, with consequent serious financial lose. The construction of new lines has at lengtl been commenced, into which all healthy families will be moved out of the infected lines, as many as possible of the old houses in which will then be destroyed and the remain ing infeeted families segreguted in one of the old lines. There is every reason to believe that this measure will be as successful in eradicating the disease from the Solong estato as it has been in the ten other tea gardens shown in 'Table $\mathbf{I}$.

The Ranganati Old Lines.

Here the disease brolse out as early as 1894, and lias continued ever since-that is, for almost twenty years - in the old lines, which have not been mored, although the new lines, only 300 yards distance, have remained free since they were built in 1895 . Owing to the old records having been lost in a fire which destroyed the hospital in March, 1908, the exact number of deaths from kala-ezar in the old lines are only available since that date, and are as follows :

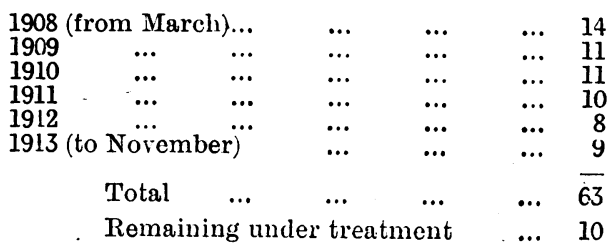

Here, again, we have a clear illustration of the con. tinued occurrence for an indefinite period of kala-azar in infected lines, which have not been dealt with by remoral of the healthy families and prevention of the admission of newly imported coolies. This instance is all the more striking from the fact that only 300 yards a way is situated the first of the newly constructed lines, from which all kala-azar cases have been carefully excluded, and which has remained quite free from the disease for no less than eighteen years, during the whote of which period cases have continued to arise yearly in the old infected lines. $\Lambda_{0}$ ain, we have here further proof of the fact that the old accimatized coolies, who have lived for years on the estate, many of them having been born and bred there, are sooner or later attacked by the deadly disease, if they con. tinue to reside in infected lines, although they seldom suffer from other serious disease, and form the most valuable and reliable portion of the working population.

The continued occurrence for from eighteen to twenty years of cases of kala-azar in the only two infected coolio lines in the Nowgong district, which have not been dealt with by means of the segregation measures, which we have shown to have been uniformly successful in the case of the ten consecutive lines in which they have been carried out, furnishes tise mest convincing evidence possible that the complete eradication of the terrible kalaazar from every garden where this plan has been futly put into execution has really been due to the methods advocated.

The Bearing of tue Success of Segregation Heasures on the Probable Mode of Infection of Kala-azar. The uniform success of the prophylactic measures, based on the observation that the infection of kala-azar clings to the houses and their sites, is a fact of great importance in considering the probable mode of infection of the disease. As it lias been proved that a distance of a few hundred yards-not more than 300 to 400 in certain in. stances--suffices for the permanent protection of coolie lines, provided no infected person is allowed to reside in them, we may exclude any mode of infection through such flying insects as mosquitos. Moreover, we have found that malarial fever soon becomes as rife in the new lines as in the old ones, for Rogers obtained a malarial infection rate among children of about 80 per cent. in both old kala-azar infected lines and in a now one which had been free from the latter disease for several years, so there could have bcea no lack of mosquitos in the new 
lines. This high endemic index accounts for the number of liala-azar patients Rogers found to be infected with malarial parasites during his first investigation in 1896 , that is, several years before the frequent malarial infection of apparently healthy people was known.

Water.

Water can be safely excluded as the vehicle of infection for several reasons. In the first place, the parasite of kala-azar is very rapidly destroyed by water, even if the temperature and other conditions are favourable. Even a little moisture on a slide will break up the organisms. Secondly, it has been shown that at Seconce segregation measures were rapidly effectual in eradicating the disease, although there was no change of the water supply during the first year after moving the lines, and only a partial change subsequently. In several of the other instances the old water supply was used for many months after the lines were moved, yet the disease rapidly declined. Thirdly, a water origin cannot explain the manner in which the disease clings to particular houses and families for years, while other houses in the same row of huts may be entirely exempt, the water supply for all being the same. That the disease was particularly bad along the banks of the Kulung river of the Nowgong district is easily understood when it is remembered that the grand trunk road of the district follows the course of the river, the banks of which are both the most densely populated area, and the one along which most of the trade occurs, affording constant'opportunities for the spread of the infection.

Diet.

Dict can also be excluded, as a result of the study of liala-azar under the favourable conditions for obtaining accurate data presented by tea estates with European doctors, especially when the same medical man has been in charge of all the gardens for sixteen years, and of most of them for twenty years, as in the case of Dodds Price. The diet of the coolies consists mainly of district grown rice, together with a certain amount imported from Calcutta. In addition dhal (a kind of pea) and vegetables are regularly consumed. Meat is indulged in very sparingly. Fish can only be obtained for a few weeks in the year, so is not an important article of diet. Some of the gardens obtain it from the Samaguri bheel (lake) and others from the Kulung river. Moreover, several gardens, one of which was not more than three miles from an infected one, have entirely escaped kala-azar, although their coolies had the same diet, including fish, as the infected ones. Again, the eradication of the disease following the segregation measures took place without any change of diet, while the disease continued in lines which were not moved, although their coolies had the same diet as those in the healthy new lines.

\section{Indicaticns for a Non-flying Insect Carrier, most} probably the Bed-bug.

Christophers, Donovan, Patton, and others have demonstrated that the kala-azar pauasite can sometimes be found in small numbers in the peripheral blood. Rogers obtained the development of the flagellate stage in sterile citrated normal saline solution kept at a temperature below $75^{\circ} \mathrm{F}$. Such a sterile saline medium is not likely to commonly occur in nature except in the stomach of some biting insect. Rogers obtained the most copions development by neutralizing or slightly acidifying the salt solution, and also found that the contents of the stomachs of bed-bugs, after suclking human blood, often showed such a reaction combined with sterility, and consequently suggested the bed-bug as the most likely carrier of the infection. Although he failed to obtain experimental proof of this theory during short leave to Assam for the purpose, yet soon after Patton, after many months' whole-time study of the problem, did succeed in occasionally demon. strating the development of the flagellate stage of the parasite in bed-bugs fed on kala azar patients who presented the parasites in their peripheral blood. More recently Patton has found that the development proceeds best if no second feed of blood is given to the insects.

It has been objected that Patton has only succeeded in obtaining a very few positive results in a long series of experiments. If we consider for a moment the epidemiological facts, this does not appear to us to be such a serious obstacle to the acceptance of the theory as it might at first sight appear. It will be evident from the data in the earlier portion of this paper that a considerable number of people may live for several years in the same lines, or even, as often happened, in the same house as other persons infected with kala-azar, and yet entirely escape the disease. The further fact that if people go on living long enough in such infected houses or lines the great majority of them do eventually contract the disease, so that after a number of years almost the entire population of a set. of contiguous huts may die of kala-azar, appears to show that the slowness of infection is not due to any lack of susceptibility to the disease. We know that in the very same lines every soul is likely to contract malaria over and over again within the same period of time. We can also testify from personal experience that bed-bugs can be collected by the score from every.coolie hut. It would appear from these facts that, if even one bed-bug in a hundred was capable of carrying the infection of kala-azer, every person in an infected house would rapidly develop the disease. Moreover, the comparative rarity of the parasites in the peripheral blood, as compared with malaria, alone accounts for much of the difficulty in experimental and natural infeetion of the insects. It would be quite sufficient for bed-bugs only very rarely to become capable of conveying the infection (as in Patton's experiments), under conditions an exact knowledge of which is not-yet available, to enable them to be efficient carriers of the disease.

In this connexion we may refer to the experiment carried out by Dodds Price, at the suggestion of Rogers, with a view to ascertaining if measures directed against the bed-bug would prove effective in freeing houses from infection. Fumigating the houses with sulphur, disinfecting the beds with solution of corrosive sublimate in boiling water, and burning old clothes were followed by the disappearance of the disease from a row of badly infected coolie huts for several years, but this measure was found to be troublesome and expensive. Moreover, cases reappeared in other parts of the lines, and the disease was not completely stamped ont. Burning the thatched roofs in the houses also failed to prevent subsequent cases occurring in them. The mud walls of these houses were over $2 \mathrm{ft}$. in thickness, and the flames died down long before the whole thickness of the walls could have been sufficiently heated to destroy all the bed-bugs within their crevices, so that the failure of this measure can easily be understood. It is also known that bed-bugs can live for many months withont food, so that the cling. ing of the infection to houses harbouring them is not surprising. Were it not for the facts now known regarding the life-history of the parasite, the evidence would go far towards incriminating the actual soil as well as the houses; but on the whole the bed-bug theory best accounts for all the known facts, including a few instances of infection of Europeans through cohabiting with native women suffering from kala-azar. The development of the parasite into the flagellate stage in bed-bugs obtained by. Patton goes very far towards establishing this theory.

In any case the invariable success in ten consecutive tea gardens where the segregation methods dealt with in this paper have been carried out, is sufficiently convincing evidence of the infectiousness of the houses, and possibly of their sites, to enable this theory to be safely acted on until such time as the problem is completely and finally solved. Unfortunately the measures, which can be adopted in tea garden coolie lines, cannot be so easily carried out in the case of infected villages or isolated sporadic cases, although the principles remain the same in either case, and further efforts in this direction are much to be desired.

The Permanency of Recoveries from Kala-azar.

Scepticism is not rarely expressed as to whether undoubted kala-azar is ever recovered from. It will be observed that we have referred to a number of such recoveries in this paper, and we wish in conclusion to emphasize the fact. In hospital practice it is only exceptionally possible to follow up patients for a sufficiently long time to prove the occurrence of complete and lasting recovery. Rogers has recorded some instances in his Fevers in the Tropics, and has notes of several European children who not only recovered but have remained quite 
well for a number of ycar's. Dodds Price, during his twenty years' experience in $\Lambda$ ssam, has followed upwards of 2,000 cases from first to last on tea estates, and can personally vouch for over 150 complete and permanent recoveries, in which the patients continued to do full work for years. Recently we examined together 14 out of the 15 recoveries on the Seconce estate, the remaining case not being at hand, although in good health. It is interest. ing to note that in five of these the spleen had entirely receded beneath the ribs, in five more the organ dil not extend more than 1 in. below the costal margin, while the largest spleen extended but 2 in. down. These coolies were all doing regular work. On other estates there are coolies working who recovered from laala-azar up to as long as fifteen years ago. The experience of us both is that if a kala-azar patient, who had reached the typical advanced stage of the disease with great emaciation, once loses the fever, puts on flesh steadily for several months, and becomes well nourished, he or she never relapses. Of course, in a comparatively early stage a patient may improve and put on weight for a time, and yet the fever may recur; but we are not referring to such. In the teagarden cases the recoveries have not followed any special line of treatment, but not infrequently occurred most unexpectedly. It sometimes followed on a septic infection, as in one of the Seconee cases, in which gangrene of the scrotum was the turning point in the course of the disease. Now that we have demonstrated the great value of segregation in the prevention of the spread of kala-azar, what is most wonted is a curative treatment.

\section{WILD GAME AS A RESERVOIR FOR HUMAN TRYPANOSOMES.}

AN ANalysis of the AvaIlable Evidence frod the NoRTherN Shores of LAKe Victoria Nyanza.

BY

\section{H. LYNDHURST DUKE, M.D., D.T.M. AND H.CAMB.}

THE question whether the wild game of the sleeping sickness areas of Africa are acting as reservoirs for the human trypanosomes, $T$. rhodesiense and $T$. gambiense, lias recently attained great importance. Among the investigators engaged in the biological problems con. nected with sleeping sickness there are two distinct opinions prevalent. On the one hand some observersforemost among them the Germans of Lake Tanganyika -are strongly of the opinion that these game trypano. somes; however similar they may seem to the human parasite, are nevertheless non-pathogenic to man; others, including the Royal Society's Commissioners in Nyasa. land and Kinghorn and Yorke, consider that certain of the trypanosomes recovered from the local game are identical with $T$. rhodesiense of man.

The special aspect of this question which will receive attention here is the part played by the game in the fly area of the northern shores of the Victoria Lake. As is well known, a terrible epidemic of sleeping sickness devastated this part of Uganda Protectorate in the years 1899-1909. The disease was presumably introduced by caravan porters from the Congo, where tiypanosomiasis has long been known to the natives. In 1908-9 the native population of the lake shore of the mainland and of the neighbouring islands was removed inland, away from the fly. Since this measure the disease has practically died out in this part of the Protectorate. In spite, howerer, of the removal of the natives from contact with the wild lake shore G. palpalis, a certain proportion of these flies are still (1912) capable of infecting monkeys with a trypanosome. The morphology and general behaviour of this organism are indistinguishable from those of T. gambiense.

Again, in September, 1911, an exactly similar trypanosome was obtained from the blood of two situtunga antelope shot on Damba Island, about nine miles from the mainland. 1 The point to be decided is: Are these "wild fly" and "situtunga" trypanosomes descendants of the T.gambiense which caused the recent epidemic, or are they merely parasites of the antelope, and not capable of surviving in a liuman host? Unfortunately, the decisive experiment of inoculating the organisms in question into man is not feasible in Uganda. There are no local rolunteers, and the ethical objections to experiments, however painless, on condemned criminals are insurmountable. All that can be done is to review the whole available evidence in the light of common sense, and to try and arrive at a logical conclusion.

For convenience, the trypanosome obtained from Damba situtunga will be referred to as the "Damba trypanosome." The organism pathogenic to monkeys and derived from wild flies will be cal!ed the "wild fly trypanosome." I hope in the course of this brief review to establish the fact that these two trypanosomes are identical; and that both are the descendants, doubtless somewhat modified, of the parasite which caused the recent epidemic. The points demanding attention will be considered in the form of a series of questions and answers.

A. Is there any reason to doubt the identity of the "Damba" trypanosome and the "wild fly" trypanosome?

I have shown that the morphology and general reactions of these two strains of trypanosomes make it impossiblo to doubt their identity. ${ }^{1}$ The answer to this important question is accordingly in the negative.

B. Is there any evidence that the trypanosome of the fly on the mainland and island coasts of Northern Lake Victoria Nyanza is derived from antelope, vather than from hippos, veptiles, or birds?

1. The "Damba trypanosome" was obtained in monkeys by direct injection of situtnnga blood.

2. Blood of a considerable number of hippos, birds, and reptiles has been injected into susceptible animals without any trypanosome being discovered.

3. On islands where there are no buck but plenty of hippos, reptiles, and birds, the tsetse are incapable of infecting clean monkeys or goats.

4. The closer the relations between antelope and tsetse, the greater the percentage of infective flies.

As far as there is any evidence, therefore, it answcrs this question in the affirmative.

C. Is there any evidence that the trypanosome of the fly is derived from truant natives?

In spite of the regulations to the contrary there has been evidence from time to time that a few individuals have visited parts of the prolibited area. Some of these have been arrested; others are, perhaps, still at large. Could these natives account for the persistence of infected fly?

The following considerations make this explanation inadequate :

1. There are very few such natives.

2. They do not visit the strips of shore on which the experimental flies are caught, for fear of being seen and arrested by the laboratory employees, who are known to visit these localities regularly in search of $\mathrm{fly}$.

3. It is improbable that these truants are sick, as they have of necessity to lead a rongh existence and to be constantly on the look out against capture.

4. The signs of recent native occupation are usually on the far side of islands, not on the mainland.

5. On certain islands where definite signs of recent native occupation have been found -for example, huts, ashes, cooking utensils, etc.- and where there are no buck, the tsetse are non-infective. On these islands there could be practically no restriction to the movements of the truants-as regards fishing, etc.-owing to the distance from the mainland. Such islands are Nsadzi and Lwagi. The flies on the neighbouring island of Kome are infective, but here situtunga are common.

6. Truant natives are notoriously addicted to night fishing, in order to escape detection. G. palpalis is not active at night.

As regards the canoc men and fly boys employed at the laboratory to obtain flies and pupae, they are lsept under constant observation and have never shown any signs of sleeping sickness. Both blood inoculation into monkeys and the examination of fresh slides were employed at frequent intervals.

It is plain from the facts here given that antelope are probably the chief reservoir for the "wild fly" trypanosome. 